\title{
4
}

\section{Responding to the Challenging Dilemma of Faculty Engagement in Research on Teaching and Learning and Disciplinary Research}

\author{
Natasha Kenny \& Frederick Evers \\ University of Guelph
}

Over the past two decades, the scholarship of teaching and learning (SoTL) has received increased attention in academe. Broadly conceptualized as an area which combines the experience of teaching with the scholarship of research, and the dissemination of this knowledge such that the broader academic community can benefit from this scholarly product, SoTL has been regarded as a primary means to increase the quality and value of teaching in higher education. This paper explores five challenges which contribute to the dilemma offaculty engagement in research on teaching and learning: limited expertise, the graduate studies culture, terminology (SoTL is widely misunderstood), reward and recognition, and time constraints. Responses to these challenges are presented in hopes of contributing to a positive dialogue for change, where faculty engagement in research on teaching and learning not only continues to grow, but becomes firmly grounded as an essential scholarly activity within higher education.

\section{Why the Dilemma?}

$\mathrm{R}$ esearch is essential to academe - it drives knowledge and represents the basis upon which innovation and change depend. Faculty are motivated by the prospects of exploring existing knowledge gaps within their field of study, through the application of acceptable and appropriate methods of data collection and analysis. Their career is inherently depen- dent upon the peer-review process, where academic research is reviewed, revised, and published to provide new and improved insights that are shared to provide disciplinary advancement. One's scholarly publication record has remained one of the primary bases upon which the faculty tenure and promotion process depends. 
There is little doubt in our minds that most faculty members are deeply committed to their teaching practice. When we engage in discussions with faculty, many express an interest in pursuing the scholarship of teaching and learning (SoTL) to enhance student learning, to actively demonstrate their commitment to teaching, and to broadly support improved teaching and learning in higher education. In a survey of over 100 medical faculty members, Zibrowski, Weston, and Goldszmidt (2008) found that an overwhelming majority (79\%) expressed an interest in engaging in educational scholarship. However, faculty often express concerns regarding their ability to actively engage in research on teaching and learning, while maintaining momentum on their disciplinary research agenda, and committing to their many other academic and service-based responsibilities. Based upon our previous academic experiences and a review of scholarly literature, we summarize and respond to five challenges to faculty engagement in research on teaching and learning in the following sections: limited expertise, the graduate studies culture, terminology (SoTL is widely misunderstood), reward and recognition, and time constraints.

\section{Limited expertise}

Because many faculty lack a background in educational research, they feel as though they have limited expertise to effectively engage in research on teaching and learning (Goldszmidt, Zimbrowski, \& Weston, 2008; McKinney, 2007; Zibrowski et al., 2008). To this point, we paraphrase the thoughts of a recent participant in the Engaging in Educational Research learning circle at our institution: "I feel very comfortable doing social science research, but I find research on teaching and learning very difficult." Although comfortable within their 'home' discipline, faculty often find the breadth of literature in higher education decidedly overwhelming. In her book Enhancing Learning through the Scholarship of Teaching and Learning, McKinney (2007) identifies in excess of 100 journals related to teaching and learning in higher education. Furthermore, given the complexity of teaching and learning issues within academe, defining a specific research problem can be extraordi- narily daunting, let alone applying valid and reliable research methods to conduct SoTL (research methods which are often clearly outside of their disciplinary expertise).

According to Goldszmidt et al. (2008), providing additional formal education may not be the answer to this challenge. They assessed the impact of an initiative where medical faculty members were sponsored by their college to complete a Master of Education. When compared with faculty who had not participated in this advanced degree program, they found that it did not result in an increase in the faculty members' level of interest or active participation in education-related research projects, funding attempts, or publications. In addition, there was no significant difference in the faculty members' perceived barriers to or support needs for encouraging their participation in educational research. Furthermore, it has been suggested that faculty with an education-related background are more likely to be appointed additional administrative and leadership roles, thereby further confounding their ability to conduct research on teaching and learning (Zibrowski et al., 2008).

Internal faculty development initiatives such as teaching scholars programs (e.g. Gruppen, Frohna, Anderson, \& Lowe, 2003; Steinert, Nasmith, McLeod, \& Conochie, 2003) and faculty certificate programs (e.g. Hubball \& Burt, 2006; Hubball \& Poole, 2003) appear to better meet the needs of faculty. These programs intentionally bring together small cohorts of faculty to explore the theories and principles of educational scholarship, actively evaluate and improve their teaching practice, and foster engagement in research on teaching and learning. Many are based upon the premise of providing an opportunity for interaction through a learning community, where faculty meet intentionally and regularly to actively dialogue and provide a sense of reciprocal support and mentorship (Blanton \& Stylianou, 2009; Hubball \& Albon, 2007; Richlin \& Cox, 2004). One of the inherent strengths of this approach is the natural collaboration that evolves between new and experienced faculty members, motivated by the common goal of improving teaching and learning in higher education. 


\section{The graduate studies culture}

Most faculty members receive very little exposure to pedagogy during their graduate studies. Kreber (2001) argues that graduate education should place an increased focus on SoTL by incorporating pedagogy courses into disciplinary curricula, encouraging manuscripts and dissertations with a focus on disciplinary pedagogical issues, formally integrating educational theory and research into graduate teaching assistant training programs, and establishing a mentorship model between graduate students and faculty members who are actively engaged in research on teaching and learning.

Momentum for enhancing the quality of pedagogical development in graduate student education has received recent attention as the Canadian Association for Graduate Studies has identified Teaching Competence as a core professional skill development area for all Canadian graduate students (CAGS, 2008). Although much focus has been placed on the role of teaching centres in providing teaching training and skill development, a concerted effort must be made to integrate pedagogical development and a scholarly teaching and learning research agenda throughout the university community, especially at the department and college levels. Here, faculty could collaborate with graduate students to share both their academic and teaching experiences, through an intentionally developed research program that actively demonstrates how research on teaching and learning can be applied to successfully support the mobilization and translation of disciplinary knowledge and expertise.

\section{Terminology: SoTL is widely misunderstood}

Many faculty are unfamiliar with the term SoTL, which is often widely misunderstood: "Using SoTL as a noun, other times as a verb or touting it as a synonym for other phenomena, is a manifestation of deeper conceptual problems within higher education. At a most basic level, attempts to delineate dimensions of SoTL too often deploy piffling or weak understandings of scholarship" (Boshier, 2009, p. 4). Boshier further notes that institutional attempts to define and operationalize SoTL can have uninten- tionally negative consequences, when tenure and promotion candidates are forced to justify and provide evidence of how their research qualifies, in accordance with a harshly pre-defined and linear SoTL framework. Akin to one's disciplinary research, we would argue that there is no linear set of established criteria for conducting SoTL research; it should rather be viewed as a 'dynamic and iterative process' of discovery (Boshier, 2009). Akerlind's (2003) categories for teaching development provide an appropriate context for the intricate nature of SoTL where, "a broader understanding of teaching may precede a broader understanding of growth and development of a teacher" (p. 389). There is no one agreed upon definition of SoTL, but Prosser (2008) summarizes by stating that SoTL is improving students' learning using evidence-based approaches.

Innovation is the foundation of discovery perhaps our attempts to define and operationalize SoTL based on a linear set of criteria have worked against the inspired sense of innovation we hope to see in higher education. We can only begin to imagine the teaching and learning innovations if faculty were inspired to apply creative disciplinary research approaches to explore the intricacies of teaching and learning in higher education.

\section{Research on teaching and learning is not adequately recognized or rewarded}

The seemingly insurmountable challenge that SoTL faces is firmly grounded in the historical professorial model of Research, Teaching, and Service that has resulted in a "conceptual isolation of teaching from the primary scholarly work of the disciplines" (Weston \& McAlpine, 2001, p. 90). In comparison to traditional disciplinary research activities, research on teaching and learning is often not recognized or rewarded as quality research. It may be viewed with cynicism by departments and colleagues, as questions of internal and external validity arise. Tangible research outcomes such as scholarly publications and presentations may not be given due credit by tenure and promotion committees. Furthermore, if research on teaching and learning is relegated to a teaching activity and a faculty member is not engaged in a defined 
teaching-stream, individual departments and committees are posed with the fundamental challenge of how to equitably evaluate these activities based upon a limited a set of criteria. Although the tenure and promotion process varies greatly between departments and institutions, faculty are likely to achieve greater recognition and reward for their disciplinary research, and therefore, are less motivated to engage in educational research.

Can the disciplinary research process lend itself to research on teaching and learning? Evers, Rush, and Berdrow (1998) developed a model of workplace skills called The Bases of Competence that includes four groupings (bases) of four or five skills each. The research that led to this model was disciplinarily-based in business and sociology, but led to enhancements in undergraduate education in terms of the skills needed to survive and thrive in today's workplace. This is but one faculty member's experience in research that lends itself well to Weston and McAlpine's (2001) notion of a, "continuum of growth toward the scholarship of teaching" (p. 91), which considers teaching in integration with rather than isolation from one's disciplinary research.

We would argue that the acts of teaching and learning are essential to the translation and mobilization of disciplinary knowledge and expertise, and thereby imperative to the discipline. If we are to commit to improving the quality of higher education and to a continuous cycle of research, discovery, and innovation within the disciplines, we must also commit to establishing a scholarly community of research on teaching and learning across the academy. Interest in SoTL is increasing, and many Canadian institutions have taken a lead in establishing funding and grant programs, departmental and institutional awards, faculty certification programs, teaching conferences, scholarly publications, and improvements to the tenure and promotion process - all dedicated to recognizing and rewarding faculty engagement in research on teaching and learning (Christensen Hughes, 2006). Although too numerous to list individually, some of the more comprehensive SoTL initiatives include the Institute for the Scholarship of Teaching and Learning at the University of British Columbia, and Institute for Scholarship of Teaching and Learning at Mount Royal University, Alberta. The Society for Teaching and Learning in Higher Education has also recently launched the Canadian Journal for the Scholarship of Teaching of Teaching and Learning. Additional financial support and coordination is warranted at both an institutional and national-level (Christensen Hughes, 2006; Poole, Taylor, \& Thompson, 2007), "to help orchestrate, support, and communicate the processes and products of SoTL more broadly" (Poole et al., 2007, p. 12).

\section{Time constraints}

Time constraints are one of the most substantial barriers to faculty engagement in scholarly activities related to teaching and learning (Goldszmidt et al., 2008; McKinney, 2007; Zimbrowski et al., 2008). Time-related barriers are complex and often intricately associated with the above four challenges as faculty express frustration over their inability to effectively dedicate time to SoTL projects, report having difficulty juggling their multiple academic, teaching, and administrative responsibilities, and lack motivation for engaging in research on teaching and learning because these activities receive very little support and recognition from their departments and colleagues (Zimbrowski et al., 2008). Faculty often feel as though SoTL is simply an add-on to their already heavy academic workloads.

In order to address this challenge, research on teaching and learning must be established as an institutional priority, both to improve the quality and value of higher education and to promote the dissemination and mobilization of disciplinary knowledge and expertise. We must engage in a quality SoTL dialogue across the institution and commit to improvement based upon the very foundations of higher education - reliable and valid research. Both financial and institutional support are critical to the success of these programs, in terms of establishing interdisciplinary funding for program development, administration, and operation, devoting release-time to encourage faculty participation in pedagogical research initiatives, and providing research support grants. 


\section{Conclusion}

We fully recognize that there is no one solution to the challenging dilemma of faculty engagement in research on teaching and learning and disciplinary research. We must collaborate to promote SoTL, and to establish a diverse range of innovative programs to encourage research on teaching and learning. As an academic community, we can take three proactive measures to support faculty engagement in research on teaching and learning: provide research support, encourage colleague interactions, and provide on-going pedagogical development opportunities. We hope that this essay will contribute to a progressive dialogue that alleviates some of the institutional challenges to faculty engagement in educational scholarship.

\section{References}

Akerlind, G.S. (2003). Growing and developing as a university teacher: Variation in meaning. Studies in Higher Education, 28(4), 375-390.

Blanton, M.L. \& Stylianou, D.A. (2009). Interpreting a community of practice perspective in discipline-specific professional development in higher education. Innovative Higher Education, 34, 79-92.

Boshier, R. (2009). Why is the scholarship of teaching and learning such a hard sell? Higher Education Research \& Development, 28(1), 1-15.

Canadian Association for Graduate Studies (CAGS). (2008). Professional skill development for graduate students. Retrieved from http://www.cags.ca/ pages/en/publications/cags-publications.php

Christensen Hughes, J. (2006). Strengthening the scholarship of teaching and learning in Canada. STLHE Newsletter, 42(1).

Evers, F.T., Rush, J.C., \& Berdrow, I. (1998). The Bases of Competence: Skills for lifelong learning and employability. San Francisco: Jossey-Bass, Inc.
Goldszmidt, M.A., Zimbrowski, E.M., \& Weston, W.W. (2008) Education scholarship: It's not just a question of 'degree'. Medical Teacher, 30, 34-39.

Gruppen, L.D., Frohna, A. Z., Anderson, R.M., \& Lowe, K.D. (2003). Faculty development for educational leadership and scholarship. Academic Medicine, 78(2), 137-141.

Hubball, H. \& Albon, S. (2007). Faculty learning communities: Enhancing the scholarship of teaching, learning and curriculum practice. Journal of Excellence in College Teaching, 18(2), 119-141.

Hubball, H. \& Burt, H. (2006). The scholarship of teaching and learning: Theory-Practice integration in a faculty certificate program. Innovative Higher Education, 30(5), 327-344.

Hubball, H. \& Poole, G. (2003). A learning-centred faculty certificate programme on university teaching. International Journal for Academic Development, 8(1/2), 11-24.

Kreber, C. (2001). The scholarship of teaching and its implementation in faculty development and graduate education. New Direction for Teaching and Learning, 86, 79-89.

McKinney, K. (2007). Enhancing learning through the scholarship of teaching and learning. Boston: Anker Publishing Company Inc.

Poole, P., Taylor, L., \& Thompson, J. (2007). Using the scholarship of teaching and learning at disciplinary, national and institutional levels to strategically improve the quality of post-secondary education. International Journal for the Scholarship of Teaching and Learning, 1(2), 1-16.

Prosser, M. (2008). The scholarship of teaching and learning: What is it? A personal view. International Journal for the Scholarship of Teaching and Learning, 2(2), 1-4. 
Richlin, L. \& Cox, M.D. (2004). Developing scholarly teaching and the scholarship of teaching and learning through faculty learning communities. New Directions for Teaching and Learning, 97,127-135.

Steinert, Y., Nasmith, L., McLeod, P.J., \& Conochie, L. (2003). A teaching scholars program to develop leaders in medical education. Academic Medicine, 78(2), 142-149.

Weston, C.B. \& McAlpine, L. (2001) Making explicit the development towards the scholarship of teaching. New Direction for Teaching and Learning, 86, 89-97.

Zibrowski, E.M., Weston, W.W., \& Goldszmidt, M.A. (2008). 'I don't have time': Issues of fragmentation, prioritization and motivation for education scholarship among medical faculty. Medical Education, 42, 872-878.

\section{Biographies}

Natasha Kenny is an Educational Developer in Teaching Support Services at the University of Guelph. She has an interdisciplinary background in educational development, environmental science, and landscape architecture. Her current scholarly interests relate to enhancing faculty and graduate student pedagogical development through the scholarship of teaching and learning.

Frederick Evers is the Director of Teaching Support Services and a Professor in the Department of Sociology and Anthropology at the University of Guelph. His current scholarly interests relate to student transition from school to work and faculty engagement in the scholarship of teaching and learning. 